in $\mathrm{CO}_{2}$ Activation and Utilization, supported by IUPAC under the New Directions in Chemistry (NDC) scheme, was organized as a full-day session of ICOMC 2018 on Monday, receiving good interest and attendance. The Session focused on the latest developments in $\mathrm{CO}_{2}$ utilization by reduction and addition processes, and many state-of-the-art results were shown by the invited and selected speakers. Keynote lectures were given by Thibault Cantat (CEA Saclay, France) and Yuichiro Himeda (AIST Tsukuba, Japan). This area of research was also well represented in the poster sessions. Similarly, a symposium was organized on Tuesday addressing the area of Photovoltaics and Photoactivated Chemical Processes. For this event, a keynote lecture was delivered by Curtis Berlinguette (UBC Vancouver, Canada). During the breaks, the organizers often received enthusiastic comments by many participants on the choice and variety of the scientific program and research areas represented during ICOMC 2018.

IUPAC support included the participation of a Young Lecturer and four Young Scientists showing either poster or flash presentations. On the opening day, Pietro Tundo (IUPAC Representative, Italy) gave an overview talk on the structure and current activities of IUPAC.

To make the Florence experience memorable from more than just a scientific point of view, a welcome cocktail was offered in the venue park on the opening day and a banquet was organized on Thursday evening in the adjacent Fortezza da Basso, the old Medici family fortress now used as tourist site and exhibition center. Accompanying persons were offered a choice of guided tours in Florence taking place during three of the five days of conference works. As is tradition, Wednesday afternoon was kept free from programming to allow the participants either to enjoy Florence at their own leisure or to join an excursion to the towns of San Gimignano or Chianti Area and Monteriggioni walled town. All these side events were highly praised by the participants.

The next edition of ICOMC will be held in Shanghai, China, in July 2020, co-chaired by Shuli You and Yong Tang, Shanghai Institute of Organic Chemistry, Chinese Academy of Sciences. This will certainly be another milestone event and an occasion to meet colleagues and establish new collaborations and friendships, as we trust happened during ICOMC 2018 in Florence.

Luca Gonsalvi <l.gonsalvi@iccom.cnr.it> was Scientific Secretary ICOMC 2018 and Symposium Chair. He and his co-authors are affiliated with the Consiglio Nazionale delle Ricerche, Istituto di Chimica dei Composti Organometallici in Firenze, Italy, and Maurizio Peruzzini is also affiliated with the Consiglio Nazionale delle Ricerche, Dipartimento di Scienze Chimiche e Tecnologie dei Materiali, in Roma, Italy.

\section{Congreso Latino Americano de Química}

\section{by Javier Garcia Martinez}

CLAQ (Congreso Latino Americano de Química) is the main chemistry meeting in Latin America. It is held every two years, in combination with the General Assembly of the Federation of the American Chemistry Societies. The most recent one was held in La Habana, Cuba, 8-12 October 2018. Over 1000 people attended this major meeting in the Palacio de Congresos de La Habana. There was a significant participation of young people from the region, especially Cuba, and the scientific program was very good with outstanding plenary speakers, including Jean-Pierre Sauvage (Nobel Laurate, University of Strasbourg, France), Benjamin G. Davis (University of Oxford, UK), Wolfram Sander (Ruhr-University Bochum, Germany) and Alessandro Gandini (Universidade de São Paulo, Brazil).

IUPAC was present in the Opening Ceremony and was given the opportunity to address all the participants. I had the honor, as its representative to Latin America, to present IUPAC mission, structure, and activities, focusing on what we are organizing for the IUPAC centenary and the 2019 International Year of the Periodic Table (IYPT). I also announced the next four winners of the Periodic Table of Younger Chemists

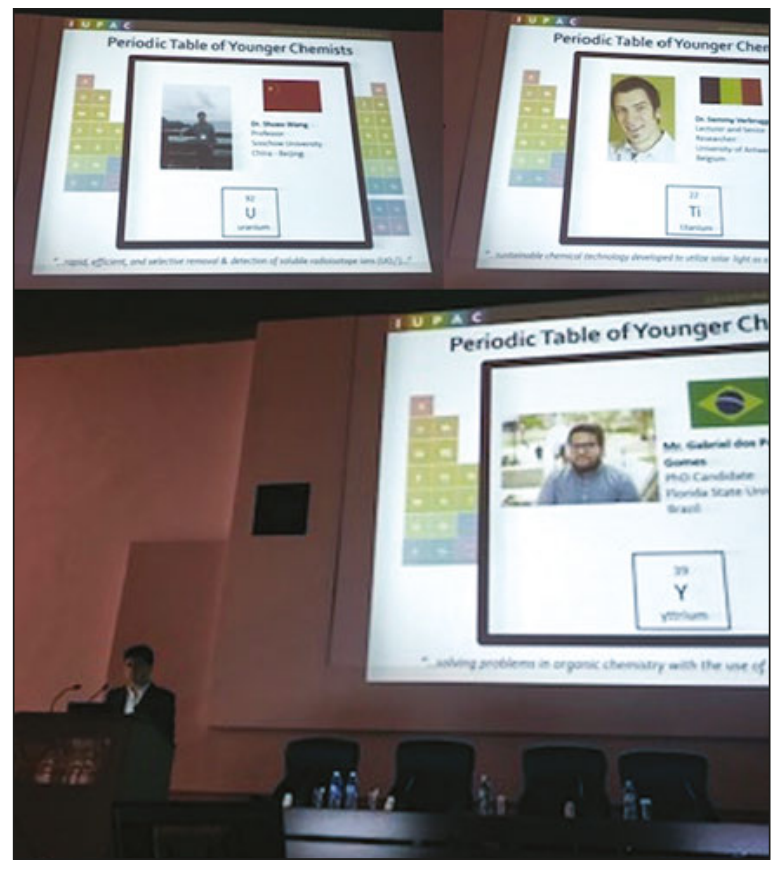

Javier Garcia Martinez announces four new additions to The Periodic Table of Younger Chemists during his address to the conference participants at the Congreso Latino Americano de Química. 


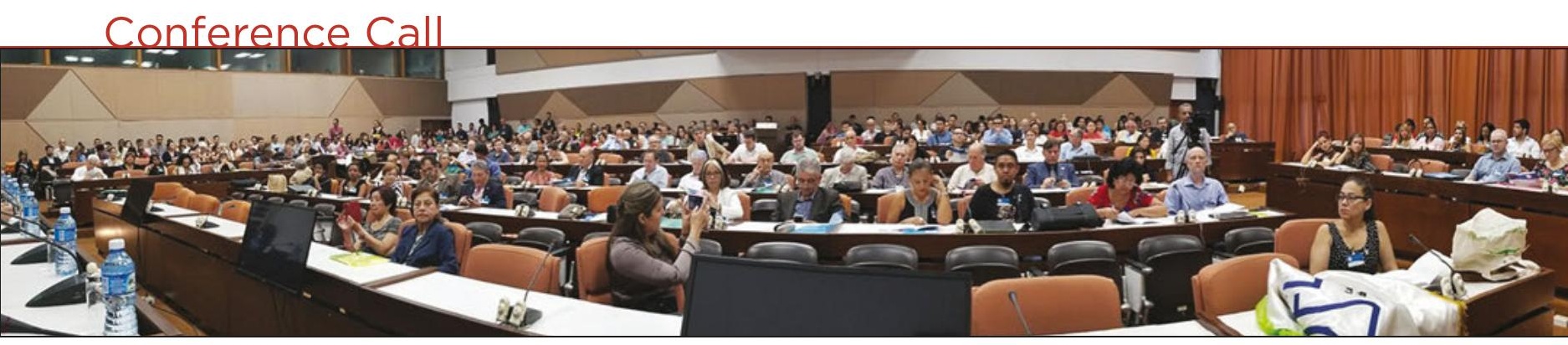

(see box below). This activity is giving IUPAC a lot of visibility as it is recognizing young chemists in some of the major chemistry events. I used this opportunity to encourage nominations from nearby regions. The impact of this activity is clear as evidenced by how social media is responding to our posts, and by the number of nominations received for each element. Other activities like the Global Breakfast, IUPAC Stories, and the Periodic Table Challenge also got a lot of attention and I had several questions from representatives from universities and chemical societies about these activities.

One important meeting I attended was with the Presidents of the Latin American Chemical Societies. After the CLAQ General Assembly was concluded, the representatives from the ACS, RSC and IUPAC were invited to address the Assembly, and a good discussion continued after our presentations. I encouraged the different chemical societies represented there to organize their own activities at local, national, and regional levels and to keep us informed. Brazil is organizing a major educational activity regarding the periodic table through their Ministry of Education for high school students. This meeting was an excellent opportunity to respond to any questions and concerns and to invite the different chemical societies from the region to engage in our activities and organize their own.

During these four days, I had the opportunity to meet numerous people and coordinate actions to increase their participation in IUPAC, to extend our membership, and to find potential sponsors. I also had several informal meetings with Bonnie Charpentier (President Elect of ACS) and Alejandra Palermo (representative from RSC). I thanked them for everything their organizations are doing to promote and complement what IUPAC is doing regarding IUPAC100 and IYPT. They asked me how they can further help and I indicated that by spreading the word about the activities we are organizing, and letting us know what they are doing, we can better use our resources and communication tools to support each other.

I believe that attending these regional meetings is critical to engage with our stakeholders, promote IUPAC activities and potentially increase our membership. As always, please do not hesitate to contact me if you have any questions. I would like to use this opportunity, on behalf of IUPAC, to thank the organizers of the CLAQ, the Cuban Society of Chemistry, for their kind invitation and for organizing such a nice conference, which will, no doubt, contribute to the development of chemistry in the region.

Javier García Martinez <j.garcia@ua.es> is an IUPAC Executive Committee Member and Professor of Chemistry at the University of Alicante, Spain.

\section{\#PTChemists}

- Zr, Dr. Claudia Bonfio, Italy

Bonfio is a Postdoctoral Research Fellow at MRC Laboratory of Molecular Biology focusing on identification of key molecular pathways in prebiotic chemistry.

\section{- U, Dr. Shuao Wang, China}

Wang is a Professor at Soochow University focusing on rapid, efficient, and selective removal \& detection of soluble radioisotope ions.
- Ti, Dr. Sammy Verbruggen, Belgium

Verbruggen is a Lecturer and Senior Researcher at the University of Antwerpen focusing on sustainable chemical technology developed to utilize solar light as a clean source of energy.

- Y, Mr. Gabriel dos Passos Gomes, Brazil Gomes is a PhD Candidate at Florida State University focusing on solving problems in organic chemistry with the use of computational tools. 